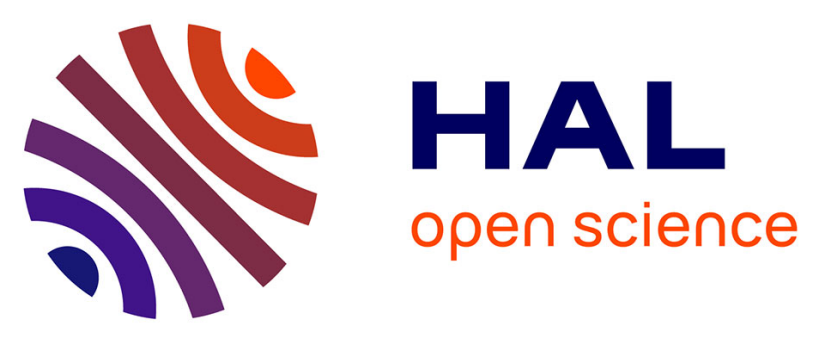

\title{
Gas-Phase Collision Induced Dissociation Mechanisms of Peptides: Theoretical and Experimental study of N-Formylalanylamide Fragmentation
}

Daniel Ortiz, Pablo Martin-Gago, Antoni Riera, Kihyung Song, Jean-Yves Salpin, Riccardo Spezia

\section{To cite this version:}

Daniel Ortiz, Pablo Martin-Gago, Antoni Riera, Kihyung Song, Jean-Yves Salpin, et al.. Gas-Phase Collision Induced Dissociation Mechanisms of Peptides: Theoretical and Experimental study of NFormylalanylamide Fragmentation. International Journal of Mass Spectrometry, 2013, 335, pp.33-44. 10.1016/j.ijms.2012.11.001 . hal-00796097

\section{HAL Id: hal-00796097 https://hal.science/hal-00796097}

Submitted on 5 Oct 2018

HAL is a multi-disciplinary open access archive for the deposit and dissemination of scientific research documents, whether they are published or not. The documents may come from teaching and research institutions in France or abroad, or from public or private research centers.
L'archive ouverte pluridisciplinaire HAL, est destinée au dépôt et à la diffusion de documents scientifiques de niveau recherche, publiés ou non, émanant des établissements d'enseignement et de recherche français ou étrangers, des laboratoires publics ou privés. 


\section{Gas-Phase Collision Induced Dissociation Mechanisms}

of Peptides. Theoretical and Experimental Study of $N$ -

Formylalanylamide Fragmentation.

Daniel Ortiz ${ }^{1,2}$, Pablo Martin-Gago ${ }^{3}$, Antoni Riera ${ }^{3}$, Kihyung Song ${ }^{4}$, Jean-Yves Salpin ${ }^{* 1,2}$ and Riccardo

$$
\text { Spezia }^{* 1,2}
$$

1) Université d'Evry Val d'Essonne - Laboratoire Analyse et Modélisation pour la biologie et l'Environnement, Boulevard François Mitterrand, 91025 Evry Cedex (France).

2) CNRS- UMR 8587.

3) Institute for research in Biomedicine (IRB Barcelona) and Departament de Química Orgànica, Universitat de Barcelona. Baldiri Reixac, 10, E-08028 Barcelona (Spain).

4) Department of Chemistry, Korea National University of Education, Chungbuk (Korea)

Correspondence to:riccardo.spezia@univ-evry.fr; jean-yves.salpin@univ-evry.fr 


\begin{abstract}
In order to shed light on the fragmentation mechanisms occurring during the collision induced dissociation (CID) of peptides in the gas phase, we have studied a peptidic model system, the $N$ Formylalanylamide (HCO-Ala- $\left.\mathrm{NH}_{2}\right)$, by coupling experimental and theoretical methods. In particular, we have addressed two different questions arising in such experiments: i) what is (are) the structure(s) of the ion before collision, and ii) what are the fragmentation mechanisms occurring after collision with the target gas. For the first question, we coupled the potential energy surface (PES) study done by means of density functional theory (DFT), with InfraRed Multiple Photon Dissociation (IRMPD) spectroscopy. For the second problem, which is actually the main topic of the present work, we coupled quantum mechanics plus molecular mechanics $(\mathrm{QM}+\mathrm{MM})$ direct chemical dynamics simulations with tandem mass spectrometry (MS/MS). In addition, in order to better delineate the fragmentation mechanisms and validate those proposed by simulations, isotopic labeling experiments using ${ }^{2} \mathrm{H}$ and ${ }^{13} \mathrm{C}$ were performed. Thanks to the interplay between simulations and experiments, it was possible to successfully identify the fragmentation pathways leading to $\mathrm{b}_{1}, \mathrm{y}_{1}, \mathrm{a}_{1}$ and immonium ions. Our mechanisms support the "mobile proton" picture that is supposed to trigger the peptide fragmentation in the gas phase, confirming, from a chemical dynamics point of view, previous theoretical and experimental studies on similar systems.
\end{abstract}

Keywords: Collision Induced Dissociation; Peptide gas phase fragmentation; Molecular dynamics; Infra Red Multiple Photon Dissociation; QM+MM chemical dynamics 


\section{INTRODUCTION}

Protein identification in proteomics is primarily based on sequencing of proteolytic peptides by means of tandem mass spectrometry (MS/MS).[1-3] In these experiments, ions are usually sampled from a atmospheric-pressure electrospray source into the first mass analyzer that is operated in the mass filter mode to selectively transmit the desired precursor ions. The selected ions are accelerated into the collision cell where excitation and dissociation take place by collision-induced dissociation (CID). The second mass analyzer is used to record the $\mathrm{m} / \mathrm{z}$ values of the dissociation products.[4] In the limit of low-energy collisions, electronic excitation is unimportant and collisions transfer a fraction of the translational energy both to vibrational and rotational energy of the ion. Several research groups have used CID to decipher peptide sequences by means of bioinformatic tools.[5-7] These software products utilize fragmentation models to generate theoretical spectra for candidate sequences, measuring the similarity between theoretical and experimental spectra: the spectrum that best matches the experimental one is used to assign the sequence. Nevertheless, the uncertainty in the evaluation is one of the limiting factors in large-scale protein identification studies. This explains the importance of understanding the fragmentation processes of protonated peptides and, therefore, the necessity to developnew techniques in order to study CID process.

Different authors have studied fragmentation of protonated peptides obtaining different possible fragments (and fragmentation pathways). Backbone cleavage at amide bonds, leads to $\mathrm{N}$-terminal, $\mathrm{b}_{\mathrm{n}}{ }^{+}$, and C-terminal, $\mathrm{y}_{\mathrm{n}}{ }^{+}$, ions, but also, after successive decomposition $\mathrm{a}_{\mathrm{n}}{ }^{+}$ions are obtained.[8-15] In terms of decomposition leading to the losses of small neutrals, the elimination of water has long been investigated.[16, 17] Loss of $\mathrm{CO}$ was found to be coupled to proton mobility in protonated diglycine $[18,19]$ and the same loss of $\mathrm{CO}$ was obtained from the intermediate oxazolone structure by Paisz et al.[20] Oxazolone structure (a cyclic type b ion) formation was described in detail by Paisz et al. through accurate quantum chemical calculations for $\mathrm{HCO}-\mathrm{CH}_{2}-\mathrm{CO}-\mathrm{NH}_{2}$ and $\mathrm{MeCO}-\mathrm{CHMe}-\mathrm{CO}-$ 
$\mathrm{NH}_{2}$.[21] Note that the formation of such oxazolone structure was first proposed by Harrison and coworkers [22] and later the first evidence was provided by IRMPD experiments by Polfer et al.[23] Finally, the loss of N-terminal acyl (formyl) group was reported by Komaromi et al.[24] in a model study of N-acetyl O-methoxy proline where it was pointed out a competition between low energy process, leading to methanol loss and high energy process, leading to ketene loss. The lacking of ammonia elimination from the N-terminal side was explained as due to the lack of stable fragments and presence of competitive exit channels.[25, 26]

A crucial step in the peptide fragmentation mechanisms is attributed to the proton mobility induced by energy activation after collision. The mobile proton model, which describes how protonated peptides dissociate under low-energy collisions, has been described by several groups by both theoretical and experimental methods.[27-32] In protonated peptidic systems, the added proton moves through protonation sites allowing charge-directed fragmentations. Paizs, Suhai and coworkers described a theoretical model [28] in which the proton transfer processes connect different protonation sites of protonated diglycine. Both, RRKM and DFT calculations were used to conclude that the proton transfers between conformers were found to be fast with relatively low energy barriers. Furthermore, when CID occurs the internal energy of the ion increases upon excitation. Consequently, energetically less favored protonation sites become more populated. This means that for systems like peptides, where different protonation sites are available, they become, after activation, energetically accessible.

The molecular picture of these mechanisms being clarified by studies of potential energy surface (PES) and statistical unimolecular reactions (i.e. RRKM methods), we are interested in show how (and if) chemical dynamics simulations can reproduce these mechanisms and improve our knowledge on them. Chemical dynamics in the gas phase, in fact, can be seen as a complementary picture of PES and RRKM studies, in providing non-statistical or non-kinetics effects or more in general the "short" time-scale behavior of chemical reactions. Example can be found in the case of $\left[\mathrm{Ca}(\text { urea) }]^{2+} \mathrm{CID}\right.$ fragmentation 
mechanisms, [33] shattering mechanism in surface induced dissociation (SID) of protonated octaglycine,[34] CID and SID of protonated glycine,[35] $\mathrm{CID}$ of $\mathrm{CH}_{3} \mathrm{SH}^{+}, \mathrm{CH}_{3} \mathrm{SCH}^{3+}, \mathrm{Cr}^{+}(\mathrm{CO})_{6}$, $\mathrm{H}_{2} \mathrm{CO}^{+}$and protonated urea.[36-42]

In the present work we have focused our attention on a synthesized model system, the NFormylalanylamide, $\mathrm{HCO}-\mathrm{Ala}-\mathrm{NH}_{2}$ (shown in Figure 1), that is a multifunctional peptide model bearing four protonation sites. Due to the relatively small size of such a model, it is possible to perform not only calculations at different theoretical levels, but also chemical dynamics. Furthermore, the relatively easy interpretation of CID and IRMPD experiments allows a full comparison between experiments and simulations.

The main purpose of the present study is to obtain a detailed picture of the reaction mechanisms involved in CID. Generally, CID experiments are interpreted by inspecting the PES that can give information on reactants, products and transition states, connecting them with satisfactory results for many systems.[43-45] Nevertheless, depending on the system, limitations must be taken into account when only the PES is considered: (i) the PES can give insights on statistical fragmentation but does not take into account any kinetic effect and (ii) all possible isomers and fragmentation pathways have to be considered. This becomes difficult for large systems not only for computational reasons but also because of conformational congestion. Direct dynamics can overcome these problems since the system (with the necessary statistical sampling) is allowed to experience pathways that are activated due to energy transfer subsequent to collision.

In the present work, we combine $\mathrm{QM}+\mathrm{MM}$ direct dynamics simulations with the aforementioned experimental techniques (CID and IRMPD) on $\mathrm{HCO}-\mathrm{Ala}-\mathrm{NH}_{2}$, which then leads to the protonated form $\left[\left(\mathrm{HCO}-\mathrm{Ala}-\mathrm{NH}_{2}\right) \mathrm{H}\right]^{+}$under electrospray conditions. Furthermore, ${ }^{2} \mathrm{H}$ and ${ }^{13} \mathrm{C}$ labeling ESI-MS/MS experiments were carried out to gain some insights about the fragmentation pathways, in order to 
confirm the results obtained from direct dynamics simulations. By coupling simulations to experiments, we were consequently able to propose consistent fragmentation mechanisms accounting for the various fragment ions observed experimentally.

\section{MATERIALS AND METHODS}

\subsection{Chemicals}

Syntheses of the products HCO-Ala- $\mathrm{NH}_{2}$ and isotopic-labeled DCO-Ala- $\mathrm{NH}_{2}$ and $\mathrm{H}^{13} \mathrm{CO}-\mathrm{Ala}-\mathrm{NH}_{2}$ were carried out as described in the Scheme 1 by using Rink Amide MBHA resin as solid support.

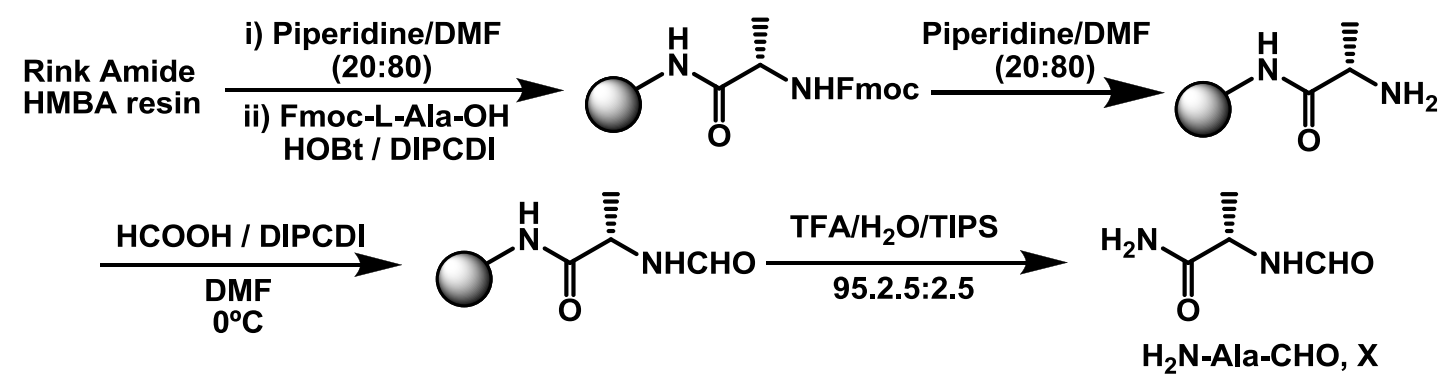

Scheme 1:Synthesis of HCO-Ala- $\mathrm{NH}_{2}(\mathrm{X})$. Labeled compounds DCO-Ala- $\mathrm{NH}_{2}(\mathrm{Y})$ and $\mathrm{H}^{13} \mathrm{CO}-\mathrm{Ala}-\mathrm{NH}_{2}$ $(Z)$ were prepared by an analogous procedure.

The coupling of the Fmoc-L-Ala-OH was done in DMF in the presence of $N, N^{\prime}-$ diisopropylcarbodiimide (DIPCDI) and 1-hydroxybenzotriazole (HOBt). Piperidine 20\% in DMF was used for Fmoc- removal. $\mathrm{N}$-Formylation of the terminal amine was accomplished in DMF at low temperature, by using a mixture of DIPCDI and formic acid $\left(\mathrm{HCOOH}, \mathrm{DCOOH}\right.$ or $\mathrm{H}^{13} \mathrm{COOH}$, respectively). Finally, treatment of the resin with a cleavage cocktail (TFA/ $\left.\mathrm{H}_{2} \mathrm{O} / \mathrm{TIPS}\right)$ allowed us to obtain the desired product with moderated yields and excellent purities. The reaction conditions as well as the NMR data are summarized in the Supporting Information (SI-A).

\subsection{Mass spectrometry Experiments}


Experiments were performed using an Applied Biosystems/MDS Sciex API2000 triple-quadrupole instrument fitted with a turboionspray ion source. Aqueous solutions of HCO-Ala- $\mathrm{NH}_{2}\left(10^{-4} \mathrm{M}\right)$ were prepared in pure water (purified with a Milli-Q water purification system) and were introduced into the source using direct infusion with a syringe pump at a flow of $5 \mu \mathrm{l} / \mathrm{min}$. Ionization of the sample was achieved by applying a voltage of $5.5 \mathrm{kV}$ on the sprayer probe and by the use of a nebulizing gas (GAS1, air) surrounding the sprayer probe, intersected by a heated gas (GAS2, air) at an angle of $90^{\circ}$. The operating pressure of GAS1 and GAS2 are adjusted to 2.1 bars, by means of an electronic board (pressure sensors), as a fraction of the air inlet pressure. The curtain gas $\left(\mathrm{N}_{2}\right)$, which prevents air or solvent from entering the analyzer region, was similarly adjusted to a value of 1.4 bars. The temperature of GAS2 was set to $100^{\circ} \mathrm{C}$. CID spectra were recorded by introducing $\mathrm{N}_{2}$ gas in the second quadrupole at a total pressure of $3 \times 10^{-5}$ mbar. Moreover, declustering potential was fixed at 20 $\mathrm{V}$ to perform MS/MS experiments. CID spectra were recorded at different collision energies ranging from 6 to $20 \mathrm{eV}$ (laboratory frame).

\subsection{IRMPD Experiments}

The present IRMPD spectroscopic investigation has been performed using an experimental platform which has been described in details previously.[46] This platform coupled a modified quadrupole ion trap (Bruker, Esquire 3000+) mass spectrometer to the IR free electron laser (FEL) of the CLIO (Centre Laser Infrarouge d'Orsay) center.[47] The FEL system is based on a 16-48 MeV linear electron accelerator where bunches of electrons are injected in the alternating magnetic field placed in the optical cavity. Wavelength tunability of this laser system is achieved at fixed electron energy by changing the gap between magnets. For the experiments in the $1100-1900 \mathrm{~cm}^{-1}$ spectral region, the electron energy was fixed at $45 \mathrm{MeV}$ and a stable average power of $800-1000 \mathrm{~mW}$ was observed.The IR FEL delivers 8 $\mu$ s long trains of macropulses at a repetition rate of $25 \mathrm{~Hz}$. Each macropulse conveys typical energies of 
$40 \mathrm{~mJ}$. A conical hole $(0.7 \mathrm{~mm}$ of diameter $)$ in the ring electrode of the trap was made in order to allow the optical access to the centre of the trap.

Multistage mass spectrometry was carried out using the standard Bruker Esquire Control (v 5.2) software. In order to record the IRMPD spectrum, the $\left[\left(\mathrm{HCO}-\mathrm{Ala}-\mathrm{NH}_{2}\right) \mathrm{H}\right]^{+}$cation was mass-selected in the $\mathrm{MS}^{1}$ step and the control of the irradiation time (typically $200 \mathrm{~ms}$ ) was obtained using the $\mathrm{MS}^{2}$ step. Mass spectra were averaged over 15 accumulations using the standard mass range (m/z 50-3000) and the normal scan resolution (13000 $\left.\mathrm{Th} \mathrm{s}^{-1}\right)$. This sequence was repeated 10 times for each recorded frequency.

\subsection{Computational details}

Potential energy surface (PES). Geometry optimizations of minima and saddle points and fragmentation products of protonated HCO-Ala- $\mathrm{NH}_{2}$ were obtained by combining the B3LYP functional [48, 49] with the $6-311++\mathrm{G}(\mathrm{d}, \mathrm{p})$ basis set. Harmonic vibrational frequencies were computed at this level, and zeropoint vibrational energy (ZPE) were added to the relative energies refined with the extended 6311++G(2df,2p) basis set. PM3 semiempirical Hamiltonian was also used, starting from B3LYP minima, to investigate the potential energy surface (PES) with the same level further used in the direct dynamics simulations. All these calculations were performed by means of Gaussian03 suite of programs.[50]

Here and hereafter we use the following nomenclature to identify each structure: the first two characters are in common for all structures $(\mathrm{AH})$ and mean protonated $(\mathrm{H})$ alanine $(\mathrm{A})$; the third character is a number which refers to the protonation site, being 1 (amide nitrogen), 2 (amide carbonyl), 3 (secondary amide) and 4 (formyl group), as shown in Figure 2; the last character is a letter denoting different conformers for the same isomer (i.e. the same protonation site). 
With the aim to describe more in detail the proton shuttling between both carbonyl groups (AH2_a, AH4_a and TS1), MP2/6-311++G(d,p) calculations were also performed.

Direct dynamicssimulations. The potential energy function for the collision system, consisting of protonated $\left[\left(\mathrm{HCO}-\mathrm{Ala}-\mathrm{NH}_{2}\right) \mathrm{H}\right]^{+}$(peptide $\left.{ }^{+}\right)$and the collision gas $(\mathrm{Ar})$ is described by:

$V=V_{\text {peptide }}+V_{\text {Ar-peptide }}$

where $V_{\text {peptide+ }}$ is the intramolecular potential of protonated $\mathrm{HCO}-\mathrm{Ala}-\mathrm{NH}_{2}$ and $V_{\text {Ar-peptide }}$ is the $\operatorname{Ar} /\left[\left(\mathrm{HCO}-\mathrm{Ala}-\mathrm{NH}_{2}\right) \mathrm{H}\right]^{+}$intermolecular potential. The PM3 semiempirical Hamiltonian has been used for the intramolecular potential. B3LYP/6-31G* intramolecular potential was also used for one short time set of simulations in order to check the reliability of PM3-based dynamics. Note that B3LYP-based chemical dynamics simulations are much more computationallyexpensive and even if based on a more reliable potential, they will necessarily suffer from a lack of enough statistical sampling.

The intermolecular potential is expressed as a sum of two-body terms between the collision gas and the atoms of $\left[\left(\mathrm{HCO}-\mathrm{Ala}-\mathrm{NH}_{2}\right) \mathrm{H}\right]^{+}$, with each two body term given by :

$$
V_{A r-p e p t i d e}=\sum_{i} A_{A r-i} e^{-B_{A r-i} r_{A r-i}}+\frac{C_{A r-i}}{r_{A r-i}^{9}}
$$

where $i$ runs over all the $\left[\left(\mathrm{HCO}-\mathrm{Ala}-\mathrm{NH}_{2}\right) \mathrm{H}\right]^{+}$atoms. This potential is purely repulsive $-\mathrm{A}, \mathrm{B}$ and $\mathrm{C}$ are always positive - and it was developed by Meroueh and Hase to simulate CID of protonated peptides.[37] Values for A,B and C are listed in the supporting information (SI-B). The same potential of Eq. 2 was recently used to simulate CID of protonated urea and [Ca(urea) $]^{2+}$, and good agreements with experimental results were obtained.[33, 36, 37]

Note that here, as previously mentioned, we used Ar in simulations while in experiments $\mathrm{N}_{2}$ is used as collision gas. As we have recently shown in a simple model case,[37] the main difference is that Ar gas 
provides a more efficient energy transfer with respect to $\mathrm{N}_{2}$ and higher reaction probability (55\% vs $30 \%$ in case of protonated urea).

Chemical dynamics simulations were performed for the following isomers: AH1, AH2_c, AH3, AH4_a, AH4_b. They correspond to the minimum energy structure in the PES for each possible protonation site. We also added the AH2_a conformer since it lies only few $\mathrm{kJ} / \mathrm{mol}$ higher in energy than AH4_a. Structures are shown in Figure 2.

Initial conditions for each isomer were chosen by adding a quasi-classical $300 \mathrm{~K}$ Boltzmann distribution of vibrational/rotational energies about the isomers potential energy minima.[51-53] Energies for the normal modes of vibration were selected from a $300 \mathrm{~K}$ Boltzmann distribution. The resulting normal mode energies were partitioned between kinetic and potential energies by choosing a random phase for each normal mode. A $300 \mathrm{~K}$ rotational energy of RT/2 was added to each principal axis of rotation for the ion. Vibrational and rotational energies were transformed into Cartesian coordinates and momenta following well-known algorithms implemented in VENUS.[54, 55] The ion was then randomly rotated about its Euler angles to take into account the random directions of the Ar + $\left.\left[\mathrm{HCO}-\mathrm{Ala}-\mathrm{NH}_{2}\right) \mathrm{H}\right]^{+}$collisions. Relative velocities were then added to the $\mathrm{Ar} /\left[\left(\mathrm{HCO}-\mathrm{Ala}-\mathrm{NH}_{2}\right) \mathrm{H}\right]^{+}$ system in accord with the center-of-mass collision energy and impact parameter. Collision energy of 8.6 $\mathrm{eV}(836.8 \mathrm{~kJ} / \mathrm{mol})$ was considered, corresponding to laboratory frame energy of $11 \mathrm{eV}(1060.0 \mathrm{~kJ} / \mathrm{mol})$. The impact parameter, b, was randomly sampled between 0 and $2.5 \AA$. The trajectories were calculated using a software package consisting of the general chemical dynamics computer program VENUS 96 coupled to MOPAC.[56] It was used to calculate the potential energy and gradient for the protonated peptide intramolecular potential. The classical equations of motion were integrated using the velocity Verlet algorithm with a time step of 0.2 fs that gives energy conservation for both reactive and nonreactive trajectories. The trajectories were initiated at an ion-projectile distance of $15 \AA$, large enough to guarantee no interaction between the ion and the colliding atom, and halted at a distance of 
$300 \AA$ to allow substantial intramolecular motion of the protonated peptide ion. This corresponds to a total integration time of about 50 ps. A trajectory was also stopped if the ion dissociates. In that case, the criterion distance of $7 \AA$ was also used to guarantee no interactions between fragments. For each isomer, approximately 5000 trajectories were performed.

The B3LYP/6-31G* chemical dynamics simulations were done using as initial structure the AH4_a isomer (the most stable form) and with same initial condition generation method as PM3-based dynamics. The VENUS 96 code [54, 55] coupled to Gaussian03 [50] was employed. In this case, due to the large computational time needed to run dynamics on such a relatively big system, only 125 trajectories were performed. Simulations were initiated at $5 \AA$ and halted at $10 \AA$ for a total simulation time of about 0.2 ps per trajectory. These results, while lacking enough statistical sampling, can give clues on reliability of PM3-based simulations.

Note that our chemical dynamics simulations model the "ideal" medium-energy single collisions, while in real experiments there are surely multiple collisions, even when the set-up tries to minimize their number (see section $\mathbf{X X}$ ). Further, other experiments in the litterature directly implement multiple lowenergy collisions to obtain fragmentation. Our simulations thus can be qualitatively comparable with experiments with fewest collisions while the comparison with multiple low-energy collision is more subtle: we are in the limit in which energy is given in a single event, thus potentially activating shorttime scale processes (and thus also non-statistical events), while experiments are (more) in the statistical (or IVR) limit.

\section{RESULTS}

\subsection{Pre-Dissociation Potential Energy Surface}


As described above, $\mathrm{HCO}-\mathrm{Ala}-\mathrm{NH}_{2}$ is a multifunctional molecule that can be protonated at various functional sites leading to several isomers. All structures (minima and transition states) and corresponding relative energies of the PES are reported in the Supporting Information (SI-C).

The full PES respect to barriers for proton transfer is reported in the Supporting Information (SI-D). Two of the most stable isomers, AH4_a and AH2_a, correspond to structures in which the proton is located in between the carbonyl groups. DFT results predict that the proton is moving from AH4_a $(0.0$ kJ/mol) to AH2_a $(2.7 \mathrm{~kJ} / \mathrm{mol})$ through a small barrier Ts1 that becomes barrierless when including zero point energy $(-2.6 \mathrm{~kJ} / \mathrm{mol})$. This is confirmed by MP2 calculations where the transition state is also located at $-0.2 \mathrm{~kJ} / \mathrm{mol}$ from AH2_a $(0.0 \mathrm{~kJ} / \mathrm{mol})$ and AH4_a $(2.3 \mathrm{~kJ} / \mathrm{mol})$. This means that before any collision, experimentally, the system should shuttle between these two structures without any energy barrier. Therefore, ions detected in positive-ion mass spectra probably correspond to a mixture between both AH4_a and AH2_a structures. On the other hand, PM3 calculations provided a barrier of 61.6 kJ/mol. This means that using the PM3 Hamiltonian, starting from AH4_a and AH2_a structures, we will underestimate this proton transfer and PM3 dynamics before any collision will not show any proton shuttling between AH4_a and AH2_a. Differences between PM3 and B3LYP PES are not only confined in proton transfer. We discuss these differences based on comparison between PM3 and B3LYP dynamics results (see Section 3.4) and careful investigation of each reaction pathways (see Section 4). Here we can anticipate that from an empirical point of view PM3 seems to be suited to describe fragmentation reactivity, since results are in agreement with experiments and with B3LYP chemical dynamics, and that this is probably due to the fact that the exit channels are reasonably well reproduced (i.e. differences with B3LYP are smaller) and that barriers to exit channels are bigger than those corresponding to proton transfer. Finally, PM3, with the aforementione exception of the proton transfer between structures AH4_a and AH2_a, underestimates energy barriers with respect to B3LYP but the profiles are similar (i.e. they proceed, after a given point of difference, in an almost "parallel" 
way) and thus we can consider that PM3 overestimates the reactivity expected from B3LYP calculations.

\subsection{IRMPD Experiments}

Before discussing fragmentation, we first report the results of IRMPD experiments that were performed in order to gain some insights about the structures that are most likely present in gas phase before collisions. Figure 3 shows the IRMPD spectrum of the protonated $\mathrm{HCO}-\mathrm{Ala}-\mathrm{NH}_{2}$ recorded upon irradiation by the IR FEL in the $1300-1800 \mathrm{~cm}^{-1}$ energy range. Assignments of the experimental IR absorption spectrum is achieved by comparison with the IR spectra obtained from DFT for the structures used later in the simulation (AH4_a, AH4_b, AH2_a, AH2_c, AH1 and AH3), For the sake of comparison, computed absorption cross-sections are represented in Figure 3 by assuming a Gaussian profile $\left(\mathrm{fwhm}=15 \mathrm{~cm}^{-1}\right.$ ) for each calculated infrared band. Experimental IRMPD spectra are obtained by plotting the photofragmentation yield $R\left(R=-\ln \left(I_{P} /\left(I_{P}+\sum I_{F}\right)\right)\right.$, where $I_{p}$ is the intensity of the precursor ion and $\Sigma \mathrm{I}_{\mathrm{F}}$ is the sum of the intensities of the fragment ions as a function of the IR radiation wavenumber. The fragmentation yield was about $20 \%$ for $\left[\left(\mathrm{HCO}-\mathrm{Ala}-\mathrm{NH}_{2}\right) \mathrm{H}\right]^{+}$using four IR-FEL macropulses, suggesting an excellent spatial overlap between the laser and the ion cloud and/or low threshold dissociation energies.[46] In the following, as far as the positions are concerned, all theoretical vibrational modes were scaled with a factor of 0.97 known to be appropriate for DFT calculations as suggested by Schlegel and coworkers. [57, 58]

The IRMPD spectrum of the protonated $\mathrm{HCO}-\mathrm{Ala}-\mathrm{NH}_{2}$ is dominated by an intense broad band centered at $\sim 1690 \mathrm{~cm}^{-1}$ that can be the superposition of both amide and formyl $\mathrm{O}=\mathrm{C}$ symmetrical stretching modes, mainly from AH2_a, AH2_c and AH4_a . These suggest that the presence of an intramolecular hydrogen bond between both carbonyl groups induces a red-shift of their (its) stretching frequencies by about $80 \mathrm{~cm}^{-1}$.[59] No experimental signals were detected above $1700 \mathrm{~cm}^{-1}$, suggesting the lack of any "free" carbonyl group, whose stretching mode is detected around and above $1800 \mathrm{~cm}^{-1}$, as observed for 
instance for protonated nucleobases [60] or small peptides.[14] (More ref here?)Another band is detected at $\sim 1600 \mathrm{~cm}^{-1}$ which may correspond to the $\mathrm{NH}_{2}$ scissoring vibrational mode in AH2_a, AH4_a and AH4_b. It is also observed a small feature at $\sim 1525 \mathrm{~cm}^{-1}$ that may be attributed to a the CNH-C antisymmetrical stretching vibrational mode in AH2_a,AH2_c, AH3 and AH4_a. The last broad band, detected experimentally around $1350 \mathrm{~cm}^{-1}$, could correspond to a $\mathrm{CH}$ bending vibrational mode and it matches with both cyclic structures AH2_a and AH4_a. In summary, it turns out from IRMPD experiments that AH2_a and AH4_a seem to be the most probable structures generated by electrospray before the collision, thereby confirming DFT calculations that predict them as the most relevant in gas phase before collision.

\subsection{Mass spectrometry and CID Experiments}

Under the electrospray conditions used, the most abundant ion observed is the protonated peptide, detected at $m / z, 117$, and at $m / z, 118$ for both $\mathrm{D}$ - and ${ }^{13} \mathrm{C}$-labeled peptides. The $\left[\left(\mathrm{HCO}-\mathrm{Ala}-\mathrm{NH}_{2}\right) \mathrm{H}\right]^{+}$ion was then selected in order to record its MS/MS spectrum (Figure 4). In addition, the use of labeled compounds allows us providing insights on the fragmentation mechanisms associated with the formation of the various product ions. CID results obtained for both unlabeled and labeled compounds are summarized in Table 1.

As shown in Figure 4a, four dissociation channels were observed. The first one $(\mathrm{m} / \mathrm{z} 100)$ corresponds to the loss of $\mathrm{NH}_{3}$ (formation of $\mathrm{b}_{1}$, Figure1). Another prominent peak is associated with the loss of carbon monoxide (formation of $\mathrm{y}_{1}$ ). The use of ${ }^{13} \mathrm{C}$-labeling unambiguously demonstrates that the labeled carbonyl group is specifically eliminated (loss of 29 Daltons). Furthermore, labeled compounds give useful information for the two remaining processes. Thus, both ${ }^{13} \mathrm{C}$ and deuterium atoms stay after fragmentation in the " $\mathrm{a}_{1}$ " fragment and consequently the $\left[\mathrm{H}_{3}, \mathrm{C}, \mathrm{O}, \mathrm{N}\right]$ moiety eliminated (loss of 45 Daltons) does not include the formyl group. The last process gives rise to the $\mathrm{m} / \mathrm{z} 44$ immonium ion $I$ through the loss of $\left[\mathrm{H}_{3}, \mathrm{C}_{2}, \mathrm{O}_{2}, \mathrm{~N}\right]$. Examination of Figure $4 \mathrm{~b}$ shows that with $\left(\mathrm{DCO}-\mathrm{Ala}-\mathrm{NH}_{2}\right)$, this 
particular process is characterized by two peaks at $\mathrm{m} / \mathrm{z} 44$ and 45 . This indicates that there are at least two fragmentation pathways for the $\boldsymbol{I}$ formation. In one of them, hydrogen atom of the formyl group is eliminated within the neutral moiety.

\subsection{Chemical dynamics simulations}

We have performed direct dynamics simulations using the six most relevant structures as starting points, namely AH4_a, AH4_b, AH2_a, AH2_c, AH1 and AH3 (Figure 2). We can distinguish three types of reactivity yields: very low reactivity $(2-3 \%)$ corresponding to initial structures in which the proton is located on the formyl group (structures AH4_a and AH4_b); medium reactivity $(14-16 \%)$ when the proton is on the amide carbonyl group (structures AH2_a and AH2_c); and finally higher reactivity for the less energetically favored structures, which are protonated onto one of the nitrogen atom (AH1 and AH3). Details on reactivity yields obtained are reported in Supporting Information (SI-E). We should note that reactivity yields depend mainly on protonation site rather than on conformation. This is due to the fact that, prior to collision, thermal energy allows each isomer to rotate along dihedral angles, like those connecting AH4_a to AH4_b or AH2_a with AH2_c. Thus, pairs of structures with similar protonation sites (AH4_a/AH4_b and AH2_a/AH2_c) give similar reactivities.

In case of AH4_a and AH2_a structures, it is expected from B3LYP and MP2 PES results that before collision the proton should shuttle within the two carbonyl groups. On the other hand, PM3 provides a barrier for this proton transfer. Consequently, PM3 dynamics did not show any proton shuttling between both structures prior collision. This corresponds to the following: we simulate collisions for both AH4_a and AH2_afixed protonation initial states as an approximation of the mixed state where the proton shuttles between the two sites. The reliability of this approximation is verified by comparing fragmentation results with experiments. We should further remark that B3LYP-based dynamics, based on a PES where the proton transfer is barrierless, did not show any such proton transfer prior collision either. 
Theoretical MS/MS spectra obtained from chemical dynamic simulations for each initial geometries are reported in Supporting information (SI-F) and summarized in table 2. All the fragments observed experimentally (see Figure 4), $\mathrm{b}_{1}, \mathrm{y}_{1}, \mathrm{a}_{1}$ and $I$ ions, are also present in the spectra obtained by chemical dynamics simulations. Three fragments, $\mathrm{a}_{1} *(\mathrm{~m} / \mathrm{z}, 74), \mathrm{X}_{0}(\mathrm{~m} / \mathrm{z}, 46)$ and $\mathrm{B}_{0}(\mathrm{~m} / \mathrm{z}, 29)$, are found in the theoretical MS/MS, at small quantity, but not observed experimentally. The $\mathrm{a}_{1}(\mathrm{~m} / \mathrm{z}, 72)$ and $I(\mathrm{~m} / \mathrm{z} 44)$ experimental fragment ions are both observed in all of the theoretical MS/MS spectra. $b_{1}$ (loss of ammonia, $\mathrm{m} / \mathrm{z}$ 100) and $\mathrm{y}_{1}$ (loss of $\mathrm{CO}, \mathrm{m} / \mathrm{z}$ 89) fragment ions are obtained mainly when AH1 and AH3 isomers are used as initial structures, respectively, but also few trajectories leading to $b_{1}$ and $y_{1}$ fragments were found when starting from AH4_a and AH4_b isomers. Note that, as shown by the pre dissociation PES (Supporting information SI-D), to achieve both fragmentations, it is necessary to convert AH4_a and AH4_b into AH1 and AH3 via sequential proton transfers. To let the system span in a statistically relevant fashion along the full PES starting from stable AH4_a and AH4_b structures, one should carry out simulations of at least one order of magnitude longer duration (we have actually performed thousands of simulation in the $10-50 \mathrm{ps}$ time length). A possible way to circumvent this brute force approach, is to observe what happens when we activate structures in the PES leading to high energy local minima. This is what we have done by performing chemical dynamics simulations with AH1 or AH3 as initial geometries.

As aforementioned, few trajectories were carried out at DTF level using AH4_a structure as initial geometry. They lead to the formation of the $\mathrm{a}_{1}\left(\mathrm{~m} / \mathrm{z}\right.$ 72) fragment but nob $\mathrm{b}_{1}$ or $\mathrm{y}_{1}$ fragments were observed. This is probably due to the limited number of trajectories and, mainly, to the shorter timelength (less than $1 \mathrm{ps}$ ) reachable by B3LYP-based dynamics. On the other hand, $\mathrm{X}_{0}(\mathrm{~m} / \mathrm{z}, 46)$ and $\mathrm{B}_{0}$ $(\mathrm{m} / z$ 29) fragments not recorded experimentally, but obtained in PM3-based dynamics, were also observed by B3LYP-based dynamics. This suggests that the observation of these fragments in chemical dynamics is not due to the use of the PM3 semiempirical Hamiltonian in simulations. 


\section{FRAGMENTATION PATHWAYS}

In order to better understand the various fragmentation pathways, we will now examine in details each fragment ion obtained, by combining results of simulations with those of experiments. The fragmentation mechanisms of $\mathbf{X}_{0}(\mathrm{~m} / \mathrm{z} 46), \mathbf{B}_{0}(\mathrm{~m} / z 29)$ and $\mathbf{a}_{1} *(\mathrm{~m} / \mathrm{z} 74)$, not observed experimentally, are reported in the supporting information (SI-G).

\subsection{Ammonia loss $(m / z, 100)$.}

From the analysis of all the chemical dynamics trajectories, it turns out that the loss of $\mathrm{NH}_{3}$ mostly arises from AH1 (87.9\%), AH4_a (7.3\%) and AH4_b (4.8\%) initial structures. When the initial structure is AH4_a or $\mathbf{A H 4} \_\mathbf{b}$, the $\mathrm{NH}_{3}$ loss is obtained through a proton transfer from the formyl group

to the amide carbonyl. Then, following the mechanism and the energy profile shown in Figure 5 (an example is also given as a movie in the supporting information; b1.mpg), the formation of oxazolone ring $(\mathbf{B})$ is obtained in near all the cases $(92 \%)$ while in the remaining $(8 \%)$ the final structure is linear (A). Note that while B3LYP and PM3 differ in providing the energy for the exit channels b1_B (corresponding to the low energy path detailed by Paisz et al. [REF], where NH3 loss and ring formation are concerted) and b1_A (corresponding to the high energy path observed in our chemical dynamics simulations where first NH3 is removed and then the ring closes), both methods report b1_B as lower in energy than b1_A.

With both labeled compounds, the observed $\mathrm{m} / \mathrm{z}$ value was 101 (neutral loss of 17 Daltons). Consequently, the proton eliminated together with the terminal amino group does not come from the formyl group. These results are consistent with the proposed mechanism shown in Figure 5.

\subsection{CO loss $(m / z ~ 89)$.}


From chemical dynamics simulations results, two different mechanisms may be proposed for the CO loss leading to the $\mathrm{y}_{1}$ ion, as reported in Figure 6. Elimination of carbon monoxide is observed almost exclusively from AH3 (98.8 \%), and to a very minor extent from AH4_a (0.6\%) and AH4_b (0.6 \%) initial structures. For the simulations starting from AH4_a and AH4_b, a proton transfer between the formyl and the amide carbonyl group occurs first, forming an AH2-like structure; then a second proton transfer leads to $\mathbf{A H 3}$. Thus the cleavage of the bond denoted $\mathbf{Y}$ is made possible leading to $\mathrm{y}_{1}$ fragment following two possible pathways: the $\mathrm{CHO}$ moiety dissociates and donates a proton (A) to the amide carbonyl $(74.0 \%)$ or $(\mathbf{B})$ to the terminal amino group $(26.0 \%)$. In the supporting information we report two prototypical movies corresponding to these mechanisms (y1_A.mpg and y1_B.mpg respectively). These mechanisms are supported by experiments with ${ }^{13} \mathrm{C}$ and ${ }^{2} \mathrm{H}$-labeled peptides. Remarkably, MS/MS spectrum of protonated DCO-Ala- $\mathrm{NH}_{2}$ indicates that deuterium and not hydrogen is transferred to the secondary amine (pathway A) or to the amide carbonyl (pathway B) as shown by the shifted $\mathrm{m} / \mathrm{z}$ 90. Moreover, $\mathrm{H}^{13} \mathrm{CO}-\mathrm{Ala}-\mathrm{NH}_{2}$ experiments reveal that the formyl carbonyl group is exclusively eliminated (neutral loss of 29 Daltons).

\section{$4.3\left[\mathrm{H}_{3}, \mathrm{C}, \mathrm{O}, \mathrm{N}\right] \operatorname{loss}(\mathrm{m} / \mathrm{z}, 72)$.}

The fragmentation product corresponding to $\mathrm{m} / \mathrm{z} 72$ has been obtained in all simulations. Surprisingly, ten different pathways leading to this fragment have been found, but two of which were observed in 99 $\%$ of the reactive trajectories and are shown in Figure 7 . When initial geometries are AH4_a and AH4_b, a proton transfer is first required. In 52\% of all cases, the proton migrates towards amide carbonyl position forming an AH2-like structure, as shown by arrow $\mathbf{1}$ in the Figure 7. In the remaining simulations a proton moves to the terminal amino group, leading to AH1-like structures, as shown by arrow 2 in the same Figure 7. In the first reaction pathway (1), following the proton transfer a direct loss of $\left(\mathrm{OH}-\mathrm{C}-\mathrm{NH}_{2}\right)$ has been recorded, as also reported in a prototypical simulation movie (supporting information; a1_1.mpg).In the second mechanism (2), after the first proton transfer, two consecutive 
losses of neutrals were observed, first ammonia and then carbon monoxide, as also shown in supporting information (movie a1_2.mpg). Remarkably, these two mechanisms are similar to those recorded from B3LYP-based chemical dynamics simulations. With both labeled compounds, the mass of the neutral fragment remains unchanged as compared to the unlabeled peptide (45 Daltons). Consequently, the neutral moiety does not incorporate the formyl group. This experimental finding is in agreement with both proposed mechanisms.

\section{$4.4\left[\mathrm{H}_{3}, \mathrm{C}_{2}, \mathrm{O}_{2}, \mathrm{~N}\right] \operatorname{loss}(\mathrm{m} / \mathrm{z}, 44)$.}

The fragment ion detected experimentally at $\mathrm{m} / \mathrm{z} 44$ corresponds to the immonium ion. It has been obtained starting from the six structures as initial structure through two different pathways (Figure 7 and 8).

The first fragmentation pathway is summarized in the Figure 7 . The proton is initially located onto the formyl group (AH4), then a proton transfer first occurs either (1) to the amide carbonyl (60\%)generating AH2-like structure or (2) to the amide nitrogen (40\%), leading to AH1 structure, as for the $\mathrm{m} / \mathrm{z} 72$ formation previously described. Then, two bonds are consecutively broken, first the bond named X breaks and then the bond named $\mathrm{Y}$ does (loss of $\mathrm{CHO}$ ). After $\mathrm{Y}$ bond cleavage, the group $\mathrm{CHO}$ leaves the molecule and a proton transfer occurs from the $\mathrm{CHO}$ to the $\mathrm{NH}$.

The second fragmentation mechanism is reported in Figure 8. When the starting structure is AH3 the fragmentation pathway starts with the cleavage of the $\mathrm{Z}$ bond followed by $\mathrm{CHO}$ dissociation. Then, two different pathways can occur, proton transfer from the $\mathrm{CHO}$ either to (1) to the amide carbonyl (72\%) followed by $\mathrm{W}$ bond cleavage (an example is shown in supporting information, I1_Sch5_A.mpg), or to (2) to the amide nitrogen (28\%) followed by two successive losses: firstly ammonia and then carbon monoxide. 
These mechanisms observed during direct dynamic simulations are again supported by isotopically labeled experiments. Remarkably, MS/MS spectra recorded with the ${ }^{13}$ C-labeled peptide exhibit a peak at $m / z 44$, indicating that the labeled formyl carbon atom is not retained in the ionic fragment, in agreement with both mechanisms proposed in Figure 8. More interesting are the deuterium-labeled experiments. If one carefully examines the mechanisms that occurred during direct dynamics simulations, it is observed that according to Scheme 4, the deuterium would be incorporated in the ionic fragment, while it is expelled according to the mechanisms depicted in Figure 8. This is perfectly consistent with experimental results, where both product ions $(\mathrm{m} / \mathrm{z} 44$ and 45$)$ were observed in the MS/MS spectrum of protonated DCO-Ala- $\mathrm{NH}_{2}$ (Figure 4b). Consequently, this suggests that both proposed mechanisms are experienced by the system while leading to the immonium ion (fragment $I$, $m / z 44)$.

\section{CONCLUSIONS}

Protonated $\mathrm{HCO}-\mathrm{Ala}-\mathrm{NH}_{2}$ has been synthesized and investigated by a combined chemical dynamics and MS/MS studies. It has been shown that the "mobile proton" model can be used in order to achieve a better understanding of the MS/MS process of protonated peptides. According to experimental and theoretical results, the added proton moves amongst the four protonation sites in $\mathrm{HCO}-\mathrm{Ala}-\mathrm{NH}_{2}$. Moreover, the fragmentation process occurs mainly by charge-directed reactions.

Remarkably, all the experimental MS/MS fragments (loss of ammonia, loss of CO, $\mathrm{a}_{1}$ and immonium formation) were successfully identified by using direct dynamic simulations. Furthermore, MS/MS of labeled peptides are in perfect agreement with the recorded fragmentation pathways for all the ions. We should note that the oxazolone structure we have identified was first proposed by Harrison [Ref JASMS 1995] and the first direct evidence pointed out by IRMPD [REF JACS 2005], and later confirmed and 
discussed by works of Maitre, Paisz and co-workers [Ref 59-61 of submitted paper] and Oomens, Polfer and co-workers [Refs 62-66 of submitted paper].

Notably, the use of a simple and approximated semi-empirical Hamiltonian for dynamics (PM3) - that is compulsory at the present time to perform a correct statistical sampling for such relatively large system - turned to be appropriate in supplying a qualitative explanation of the observed reactivity. From the comparison between DFT and PM3 PES, we can ground that on the fact that the energy barriers for dissociation are higher in energy than other those for proton transfer and that they regulate the reactivity. It resulted that, while part of the PES are quite different, two aspects suggest that PM3 dynamics is qualitatively instructive to complete the understanding of CID chemistry: (i) the exit channels (or transition states leading to a pre-dissociation) are higher in energy with respect to barriers for proton transfer (as previously found by Paisz et al. [REF]) and differences between PM3 and DFT are smaller in that part of the PES; (ii) even if a difference between PM3 and DFT is present and it can be also important in some region, the two surfaces are 'almost' parallel, i.e. they do not cross (except one case where the energy difference is small). We can further suggest that, since PM3 barriers are sistematically lower than DFT ones in the regions that determine the final fragmentation products, we overestimate reactivity at a given energy, such that what we observe can be reported to higher values of really transferred energy.

Finally, the QM+MM direct dynamics simulations of protonated CID was shown to provide a complementary picture of the M/MS fragmentation processes and rationalize experimental findings.

\section{ANKNOWLEDGEMENTS}

We thank M-P. Gaigeot for useful discussions. KS thanks UEVE for a visiting fellowship and partial support from the Basic Science Program through the National Research Foundation of Korea (KRF) administered by the Ministry of Education, Science and Technology (2012-0002654). DO and JYS thank the CLIO team (J. M. Ortega, C. Six, G. Perilhous, J. P. Berthet) as well as P. Maître, V. 
Steinmetz and O. Hernandez for their support during the experiments. This work was granted access to the HPC resources of CCRT under the allocation 2012082123 made by GENCI (Grand Equipement National de Calcul Intensif).AR and PMG thank the Spanish Ministerio de Economia y Competitividad (CTQ2011-23620), the Generalitat de Catalunya (2009SGR 00901) and IRB Barcelona for financial support.

\section{REFERENCES}

[1] R. Aebersold, D.R. Goodlett, Mass spectrometry in proteomics, Chem. Rev., 101 (2001) 269-295.

[2] K. Biemann, Contributions of mass spectrometry to peptide and protein structure, Biomed. Environ. Mass, 16 (1988) 99-111.

[3] P. Roepstorff, J. Fohlman, Proposal for a common nomenclature for sequence ions in mass spectra of peptides, Biomed Mass Spectrom, 11 (1984) 601-601.

[4] I.V. Chernushevich, A.V. Loboda, B.A. Thomson, An introduction to quadrupole-time-of-flight mass spectrometry, J. Mass Spectrom., 36 (2001) 849-865.

[5] D.N. Perkins, D.J.C. Pappin, D.M. Creasy, J.S. Cottrell, Probability-based protein identification by searching sequence databases using mass spectrometry data, Electrophoresis, 20 (1999) 3551-3567.

[6] A.R. Dongre, J.K. Eng, J.R. Yates, Emerging tandem-mass-spectrometry techniques for the rapid identification of proteins, Trends in Biotechnology, 15 (1997) 418-425.

[7] R. Craig, R.C. Beavis, TANDEM: matching proteins with tandem mass spectra, Bioinformatics, 20 (2004) 1466-1467.

[8] B.J. Bythell, D.F. Barofsky, F. Pingitore, M.J. Polce, P. Wang, C. Wesdemiotis, B. Paizs, Backbone cleavages of carbon monoxide and sequential loss and ammonia from protonated AGG: A combined tandem mass spectrometry, isotope labeling, and theoretical study, J. Am. Soc. Mass Spectrom., 18 (2007) 1291-1303.

[9] M.M. Cordero, J.J. Houser, C. Wesdemiotis, Neutral products formed during backbone fragmentations of protonated peptides in tandem mass spectrometry, Anal. Chem., 65 (1993) 15941601.

[10] I.A. Papayannopoulos, The interpretation of collision-induced Dissociation tandem Mass-Spectra of peptides, Mass Spectrom. Rev., 14 (1995) 49-73.

[11] F. Pingitore, M.J. Polce, P. Wang, C. Wesdemiotis, B. Paizs, Intramolecular condensation reactions in protonated dipeptides: Carbon monoxide, water, and ammonia losses in competition, J. Am. Soc. Mass Spectrom., 15 (2004) 1025-1038.

[12] M.J. Polce, D. Ren, C. Wesdemiotis, Special feature: Commentary - Dissociation of the peptide bond in protonated peptides, J. Mass Spectrom., 35 (2000) 1391-1398.

[13] T. Yalcin, I.G. Csizmadia, M.R. Peterson, A.G. Harrison, The structure and fragmentation of B-n $(\mathrm{n}>=3)$ ions in peptide spectra, J. Am. Soc. Mass Spectrom., 7 (1996) 233-242.

[14] B.J. Bythell, P. Maitre, B. Paizs, Cyclization and Rearrangement Reactions of a(n) Fragment Ions of Protonated Peptides, J. Am. Chem. Soc., 132 (2010) 14766-14779.

[15] D.M. Good, C. Marin-Vicente, R.A. Zubarev, Are the majority of a(2)-ions cyclic?, Phys. Chem. Chem. Phys, 12 (2010) 13372-13374.

[16] B. Balta, V. Aviyente, C. Lifshitz, Elimination of water from the carboxyl group of GlyGlyH(+), J. Am. Soc. Mass Spectrom., 14 (2003) 1192-1203. 
[17] G.E. Reid, R.J. Simpson, R.A.J. O'Hair, A mass spectrometric and ab initio study of the pathways for dehydration of simple glycine and cysteine-containing peptide $\mathrm{M}+\mathrm{H}(+)$ ions, J. Am. Soc. Mass Spectrom., 9 (1998) 945-956.

[18] B. Paizs, I.P. Csonka, G. Lendvay, S. Suhai, Proton mobility in protonated glycylglycine and Nformylglycylglycinamide: a combined quantum chemical and RKKM study, Rapid Commun. Mass Spectrom., 15 (2001) 637-650.

[19] B. Paizs, S. Suhai, Theoretical study of the main fragmentation pathways for protonated glycylglycine, Rapid Commun. Mass Spectrom., 15 (2001) 651-663.

[20] B. Paizs, Z. Szlavik, G. Lendvay, K. Vekey, S. Suhai, Formation of a(2)(+) ions of protonated peptides. An ab initio study, Rapid Commun. Mass Spectrom., 14 (2000) 746-755.

[21] B. Paizs, G. Lendvay, K. Vekey, S. Suhai, Formation of $b(2)(+)$ ions from protonated peptides: an ab initio study, Rapid Commun. Mass Spectrom., 13 (1999) 525-533.

[22] T. Yalcin, C. Khouw, I.G. Csizmadia, M.R. Peterson, A.G. Harrison, Why are B ions stable species in peptide spectra?, J. Am. Soc. Mass Spectrom., 6 (1995) 1165-1174.

[23] N.C. Polfer, J. Oomens, S. Suhai, B. Paizs, Spectroscopic and theoretical evidence for oxazolone ring formation in collision-induced dissociation of peptides, J. Am. Chem. Soc., 127 (2005) 1715417155.

[24] I. Komaromi, A. Somogyi, V.H. Wysocki, Proton migration and its effect on the MS fragmentation of N-acetyl OMe proline: MS/MS experiments and ab initio and density functional calculations, Int. J. Mass Spectrom., 241 (2005) 315-323.

[25] A.G. Harrison, A.B. Young, C. Bleiholder, S. Suhai, B. Paizs, Scrambling of sequence information in collision-induced dissociation of peptides, J. Am. Chem. Soc., 128 (2006) 10364-10365.

[26] R.A.J. O'Hair, M.L. Styles, G.E. Reid, Role of the sulfhydryl group on the gas phase fragmentation reactions of protonated cysteine and cysteine containing peptides, J. Am. Soc. Mass Spectrom., 9 (1998) 1275-1284.

[27] K.A. Cox, S.J. Gaskell, M. Morris, A. Whiting, Role of the site of protonation in the low-energy decompositions of gas phase peptide ions (vol 7, pg 522, 1996), J. Am. Soc. Mass Spectrom., 7 (1996) 759-759.

[28] I.P. Csonka, B. Paizs, G. Lendvay, S. Suhai, Proton mobility and main fragmentation pathways of protonated lysylglycine, Rapid Commun. Mass Spectrom., 15 (2001) 1457-1472.

[29] A.R. Dongre, J.L. Jones, A. Somogyi, V.H. Wysocki, Influence of peptide composition, gas-phase basicity, and chemical modification on fragmentation efficiency: Evidence for the mobile proton model, J. Am. Chem. Soc., 118 (1996) 8365-8374.

[30] A.G. Harrison, T. Yalcin, Proton mobility in protonated amino acids and peptides, Int. J. Mass Spectrom., 165 (1997) 339-347.

[31] V.H. Wysocki, G. Tsaprailis, L.L. Smith, L.A. Breci, Special feature: Commentary - Mobile and localized protons: a framework for understanding peptide dissociation, J. Mass Spectrom., 35 (2000) 1399-1406.

[32] I.P. Csonka, B. Paizs, G. Lendvay, S. Suhai, Proton mobility in protonated peptides: a joint molecular orbital and RRKM study, Rapid Commun. Mass Spectrom., 14 (2000) 417-431.

[33] R.C. Spezia, A.; Gaigeot, M-P.; Salpin, J-Y.; Song, K.; Hase, W.L., Collision Induced Dissociation of Doubly-charged Ions : Coulomb Explosion vs Neutral Loss in [Ca(urea)]2+ Gas Phase Unimolecular Reactivity via Chemical Dynamics Simulations, Phys. Chem. Chem. Phys, DOI:10.1039/C2CP41379E (2012).

[34] K. Park, B. Deb, K. Song, W.L. Hase, Importance of Shattering Fragmentation in the SurfaceInduced Dissociation of Protonated Octaglycine, J. Am. Soc. Mass Spectrom., 20 (2009) 939-948.

[35] S.O. Meroueh, Y.F. Wang, W.L. Hase, Direct dynamics Simulations of collision- and surfaceinduced dissociation of N-protonated glycine. Shattering fragmentation, J. Phys. Chem. A, 106 (2002) 9983-9992. 
[36] Y. Jeanvoine, M.-P. Gaigeot, W.L. Hase, K. Song, R. Spezia, Collision induced dissociation of protonated urea with $\mathrm{N}(2)$ : Effects of rotational energy on reactivity and energy transfer via chemical dynamics simulations, Int. J. Mass Spectrom., 308 (2011) 289-298.

[37] R. Spezia, J.-Y. Salpin, M.-P. Gaigeot, W.L. Hase, K. Song, Protonated Urea Collision-Induced Dissociation. Comparison of Experiments and Chemical Dynamics Simulations, J. Phys. Chem. A, 113 (2009) 13853-13862.

[38] O. Meroueh, W.L. Hase, Collisional activation of small peptides, J. Phys. Chem. A, 103 (1999) 3981-3990.

[39] E. Martinez-Nunez, S.A. Vazquez, J.M.C. Marques, Quasiclassical trajectory study of the collisioninduced dissociation of CH3SH++Ar, J. Chem. Phys., 121 (2004) 2571-2577.

[40] E. Martinez-Nunez, S.A. Vazquez, F.J. Aoiz, J.F. Castillo, Quasiclassical trajectory study of the collision-induced dissociation dynamics of $\mathrm{Ar}+\mathrm{CH} 3 \mathrm{SH}+$ using an ab initio interpolated potential energy surface, J. Phys. Chem. A, 110 (2006) 1225-1231.

[41] E. Martinez-Nunez, A. Fernandez-Ramos, S.A. Vazquez, J.M.C. Marques, M.Y. Xue, W.L. Hase, Quasiclassical dynamics simulation of the collision-induced dissociation of $\mathrm{Cr}(\mathrm{CO})(6)(+)$ with $\mathrm{Xe}, \mathrm{J}$. Chem. Phys., 123 (2005).

[42] J.B. Liu, K. Song, W.L. Hase, S.L. Anderson, Direct dynamics study of energy transfer and collision-induced dissociation: Effects of impact energy, geometry, and reactant vibrational mode in H2CO+-Ne collisions, J. Chem. Phys., 119 (2003) 3040-3050.

[43] I. Corral, O. Mo, M. Yanez, J.-Y. Salpin, J. Tortajada, D. Moran, L. Radom, An experimental and theoretical investigation of gas-phase reactions of Ca2+ with glycine, Chem. Eur. J., 12 (2006) 67876796.

[44] A. Eizaguirre, O. Mo, M. Yanez, J.-Y. Salpin, Modeling the interactions between peptide functions and $\operatorname{Sr}(2+)$ : formamide-Sr(2+) reactions in the gas phase, Phys. Chem. Chem. Phys, 13 (2011) 1840918417.

[45] A.M. Lamsabhi, M. Alcami, O. Mo, M. Yanez, J. Tortajada, J.-Y. Salpin, Unimolecular reactivity of uracil-Cu2(+) complexes in the gas phase, ChemPhysChem, 8 (2007) 181-187.

[46] L. Mac Aleese, A. Simon, T.B. McMahon, J.M. Ortega, D. Scuderi, J. Lemaire, P. Maitre, Mid-IR spectroscopy of protonated leucine methyl ester performed with an FTICR or a Paul type ion-trap, Int. J. Mass Spectrom., 249 (2006) 14-20.

[47] R. Prazeres, F. Glotin, C. Insa, D.A. Jaroszynski, J.M. Ortega, Two-colour operation of a FreeElectron Laser and applications in the mid-infrared, Eur. Phys. J. D., 3 (1998) 87-93.

[48] A.D. Becke, A new mixing of Hartree-Fock and local density-functional theories, J. Chem. Phys., 98 (1993) 1372-1377.

[49] C.T. Lee, W.T. Yang, R.G. Parr, Development of the Colle-Salvetti correlation-energy formula into a functional of the electron density, Phys. Rev. B, 37 (1988) 785-789.

[50] M.J. Frisch, G.W. Trucks, H.B. Schlegel, G.E. Scuseria, M.A. Robb, J.R. Cheeseman, J. Montgomery, J. A.;, T. Vreven, K.N. Kudin, J.C. Burant, J.M. Millam, S.S. Iyengar, J. Tomasi, V. Barone, B. Mennucci, M. Cossi, G. Scalmani, N. Rega, G.A. Petersson, H. Nakatsuji, M. Hada, M. Ehara, K. Toyota, R. Fukuda, J. Hasegawa, M. Ishida, T. Nakajima, Y. Honda, O. Kitao, H. Nakai, M. Klene, X. Li, J.E. Knox, H.P. Hratchian, J.B. Cross, V. Bakken, C. Adamo, J. Jaramillo, R. Gomperts, R.E. Stratmann, O. Yazyev, A.J. Austin, R. Cammi, C. Pomelli, J.W. Ochterski, P.Y. Ayala, K. Morokuma, G.A. Voth, P. Salvador, J.J. Dannenberg, V.G. Zakrzewski, S. Dapprich, A.D. Daniels, M.C. Strain, O. Farkas, D.K. Malick, A.D. Rabuck, K. Raghavachari, J.B. Foresman, J.V. Ortiz, Q. Cui, A.G. Baboul, S. Clifford, J. Cioslowski, B.B. Stefanov, G. Liu, A. Liashenko, P. Piskorz, I. Komaromi, R.L. Martin, D.J. Fox, T. Keith, M.A. Al-Laham, C.Y. Peng, A. Nanayakkara, M. Challacombe, P.M.W. Gill, B. Johnson, W. Chen, M.W. Wong, C. Gonzalez, J.A. Pople, Gaussian Program Suite, in: Gaussian 03, Gaussian, Inc., Wallingford,CT, 2004.

[51] S. Chapman, D.L. Bunker, An exploratory study of reactant vibrational effects in $\mathrm{CH} 3+\mathrm{H} 2$ and its isotopic variants, J. Chem. Phys., 62 (1975) 2890-2899. 
[52] W.L. Hase, Y.J. Cho, Trajectory studies of $\mathrm{S}(\mathrm{N}) 2$ nucleophilic substitution. 3. Dynamic stereochemistry and energy-transfer pathways for the $\mathrm{Cl}-+\mathrm{CH} 3 \mathrm{Cl}$ association and direct substitutionreactions, J. Chem. Phys., 98 (1993) 8626-8639.

[53] C.S. Sloane, W.L. Hase, On the dynamics of state selected unimolecular reactions: Chloroacetylene dissociation and predissociation, J. Chem. Phys., 66 (1977) 1523-1533.

[54] X.C. Hu, W.L. Hase, T. Pirraglia, Vectorization of the General Monte Carlo Classical Trajectory Program VENUS, J. Comput. Chem., 12 (1991) 1014-1024.

[55] W.L. Hase, Duchovic, R,J.; Hu, X.; Komornicki, A.; Lim, K.;Lu, D-H.; Peslherbe, G.H.; Swamy, K.N.; Vande Linde, S.R.; Wang, H.;Wolf, R.J., VENUS96, a General Chemical Dynamics Computer Program, QCPE, 16 (1996).

[56] J.J.P. Stewart, Special Issue -MOPAC- A semiempirical molecular-orbital program, J. Comput.Aided Mol. Des., 4 (1990) 1-45.

[57] M.D. Halls, H.B. Schlegel, Comparison of the performance of local, gradient-corrected, and hybrid density functional models in predicting infrared intensities, J. Chem. Phys., 109 (1998) 10587-10593.

[58] M.D. Halls, J. Velkovski, H.B. Schlegel, Harmonic frequency scaling factors for Hartree-Fock, SVWN, B-LYP, B3-LYP, B3-PW91 and MP2 with the Sadlej pVTZ electric property basis set, Theoret. Chem. Acc., 105 (2001) 413-421.

[59] B. Lucas, G. Gregoire, J. Lemaire, P. Maitre, J.M. Ortega, A. Rupenyan, B. Reimann, J.P. Schermann, C. Desfrancois, Investigation of the protonation site in the dialanine peptide by infrared multiphoton dissociation spectroscopy, Phys. Chem. Chem. Phys, 6 (2004) 2659-2663.

[60] J.Y. Salpin, S. Guillaumont, J. Tortajada, L. MacAleese, J. Lemaire, P. Maitre, Infrared spectra of protonated uracil, thymine and cytosine, ChemPhysChem, 8 (2007) 2235-2244.

[61] B. Paizs, B.J. Bythell, P. Maitre, Rearrangement Pathways of the a(4) Ion of Protonated YGGFL Characterized by IR Spectroscopy and Modeling, J. Am. Soc. Mass Spectrom., 23 (2012) 664-675.

[62] R.K. Sinha, U. Erlekam, B.J. Bythell, B. Paizs, P. Maitre, Diagnosing the Protonation Site of b (2) Peptide Fragment Ions using IRMPD in the X-H (X = O, N, and C) Stretching Region, J. Am. Soc. Mass Spectrom., 22 (2011) 1645-1650.

[63] U. Erlekam, B.J. Bythell, D. Scuderi, M. Van Stipdonk, B. Paizs, P. Maitre, Infrared Spectroscopy of Fragments of Protonated Peptides: Direct Evidence for Macrocyclic Structures of b(5) Ions, J. Am. Chem. Soc., 131 (2009) 11503-11508.

[64] X. Chen, L. Yu, J.D. Steill, J. Oomens, N.C. Polfer, Effect of Peptide Fragment Size on the Propensity of Cyclization in Collision-Induced Dissociation: Oligoglycine b(2)-b(8), J. Am. Chem. Soc., 131 (2009) 18272-18282.

[65] J. Grzetic, J. Oomens, Spectroscopic Evidence for an Oxazolone Structure in Anionic b-Type Peptide Fragments, J. Am. Soc. Mass Spectrom., 23 (2012) 290-300.

[66] M.J. Kullman, S. Molesworth, G. Berden, J. Oomens, M. Van Stipdonk, IRMPD spectroscopy b(2) ions from protonated tripeptides with 4-aminomethyl benzoic acid residues, Int. J. Mass Spectrom., 316 (2012) 174-181.

[67] M. Tirado, J. Rutters, X. Chen, A. Yeung, J. van Maarseveen, J.R. Eyler, G. Berden, J. Oomens, N.C. Polfer, Disfavoring Macrocycle b Fragments by Constraining Torsional Freedom: The "Twisted" Case of QWFGLM b(6), J. Am. Soc. Mass Spectrom., 23 (2012) 475-482.

[68] S. Zou, J. Oomens, N.C. Polfer, Competition between diketopiperazine and oxazolone formation in water loss products from protonated ArgGly and GlyArg, Int. J. Mass Spectrom., 316 (2012) 12-17. 


\section{FIGURE AND TABLE CAPTIONS}

Figure 1: Sequence ions in (HCO-Ala- $\left.\mathrm{NH}_{2}\right)$ following the peptide fragmentation nomenclature.[3] Red numbers show the different protonation sites taken into account, namely amide nitrogen (1), amide carbonyl (2), amide nitrogen (3) and formyl group (4).

Figure 2: Optimized structures for protonated $\left(\mathrm{HCO}-\mathrm{Ala}-\mathrm{NH}_{2}\right)$. Energies, in parenthesis, are in $\mathrm{kJ} / \mathrm{mol}$.

Figure 3: Experimental IRMPD a) and theoretical IR spectra b-g) of [(HCO-Ala-NH $\left.\left.\mathrm{N}_{2}\right) \mathrm{H}\right]^{+}$. Calculations are carried out at the B3LYP/6-311++G(d,p) level of theory. The experimental spectrum of panel a is superimposed in light gray over each theoretical spectrum.

Figure 4: Energy profile associated for dissociation mechanism for formation of $b_{1}$ ion. It was calculated at B3LYP/6-311++G(2df,2p)//B3LYP/6-311++G(d,p)+ZPE level (in black and continuous profile) and PM3 level (in green and non-continuous profile). 
Figure 5: Energy profile associated for dissociation mechanism for formation of $\mathrm{y}_{1}$ ion. The numbers on the arrows represent the proton transfer from $\mathrm{CHO}$ moiety to the (1) amide carbonyl and (2) secondary amine. It was calculated at B3LYP/6-311++G(2df,2p)//B3LYP/6-311++G(d,p)+ZPE level (in black and continuous profile) and PM3 level (in green and non-continuous profile).

Figure 6: Energy profile associated for dissociation mechanism for formation of $\mathrm{a}_{1}$ and $I$ ions. The numbers on the arrows represent the proton transfer from the formyl group to the (1) amide carbonyl and (2) amide nitrogen. It was calculated at B3LYP/6-311++G(2df,2p)//B3LYP/6-311++G(d,p)+ZPE level (in black and continuous profile) and PM3 level (in green and non-continuous profile).

Figure 7: Energy profile associated for dissociation mechanism for formation of $I$ ion. The numbers on the arrows represent the proton transfer from the formyl group to the (1) amide carbonyl and (2) amide nitrogen. It was calculated at B3LYP/6-311++G(2df,2p)//B3LYP/6-311++G(d,p)+ZPE level (in black and continuous profile) and PM3 level (in green and non-continuous profile).

Table 1: Product ions observed experimentally during the fragmentation of protonated $\mathrm{HCO}-\mathrm{Ala}-\mathrm{NH}_{2}$.

Table 2: Comparison between both theoretical and experimental MS/MS depending on the starting structure of protonated $\mathrm{HCO}-\mathrm{Ala}-\mathrm{NH}_{2}$. 


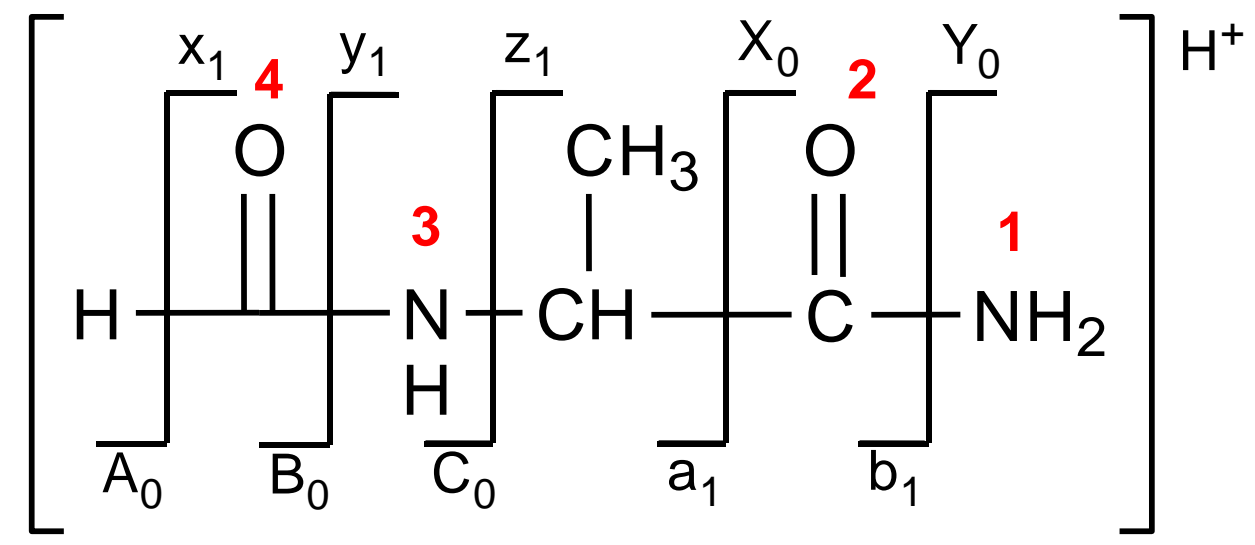

Figure 1 

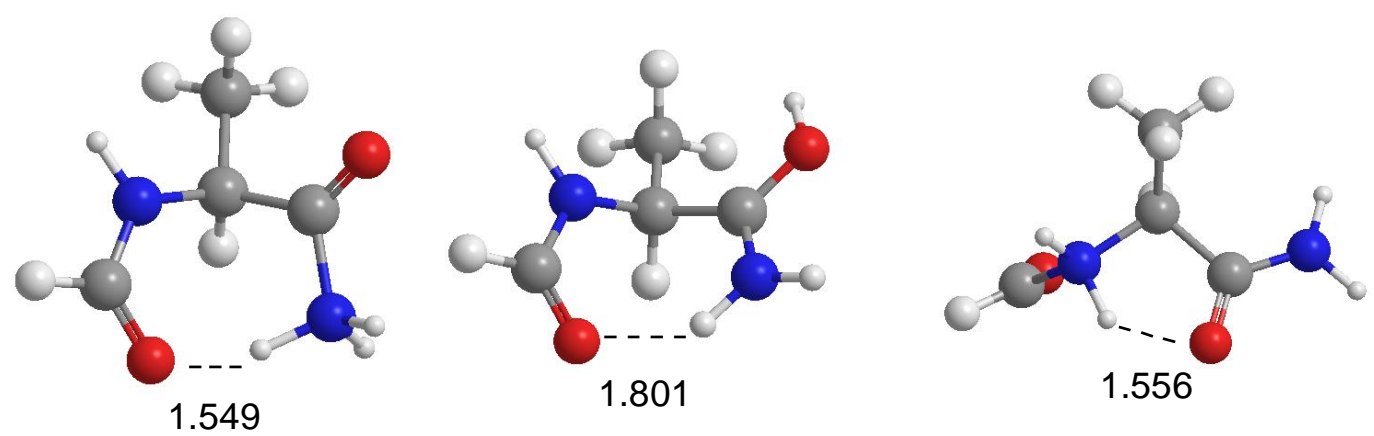

AH1 (68.9)

$$
\mathrm{AH} 2 \_\mathrm{c} \text { (32.4) }
$$

AH3 (79.3)
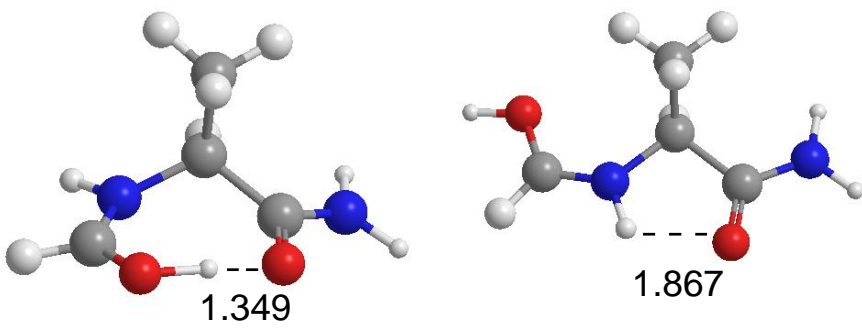

AH4_a (0.0)

AH4_b (23.7)

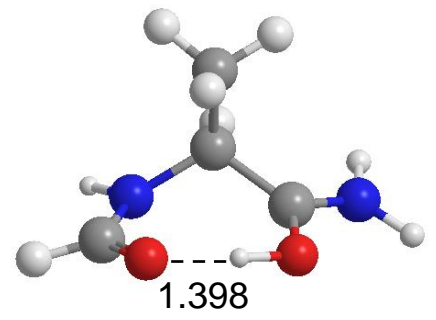

AH2_a (2.7)

Figure 2 


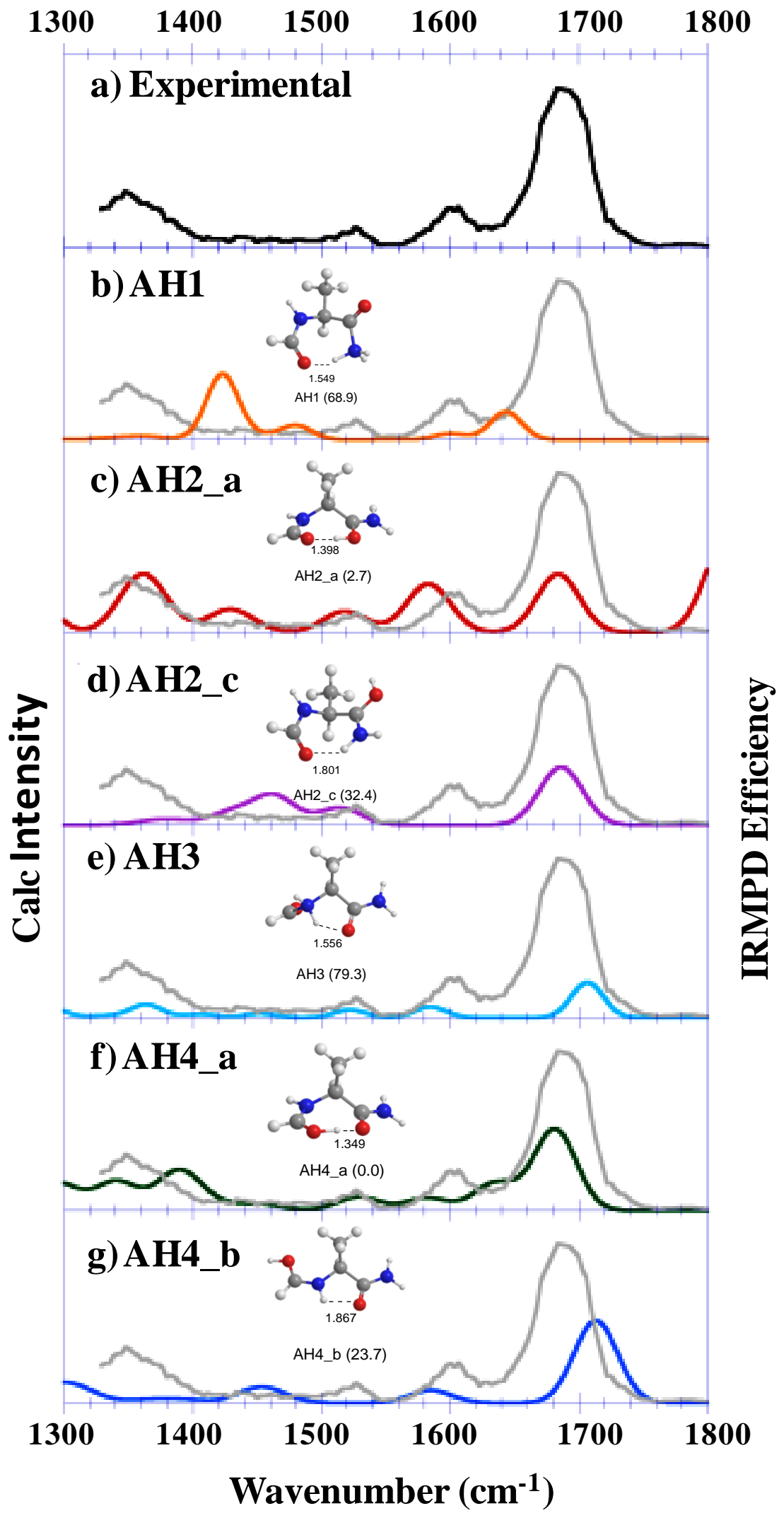

Figure 3 

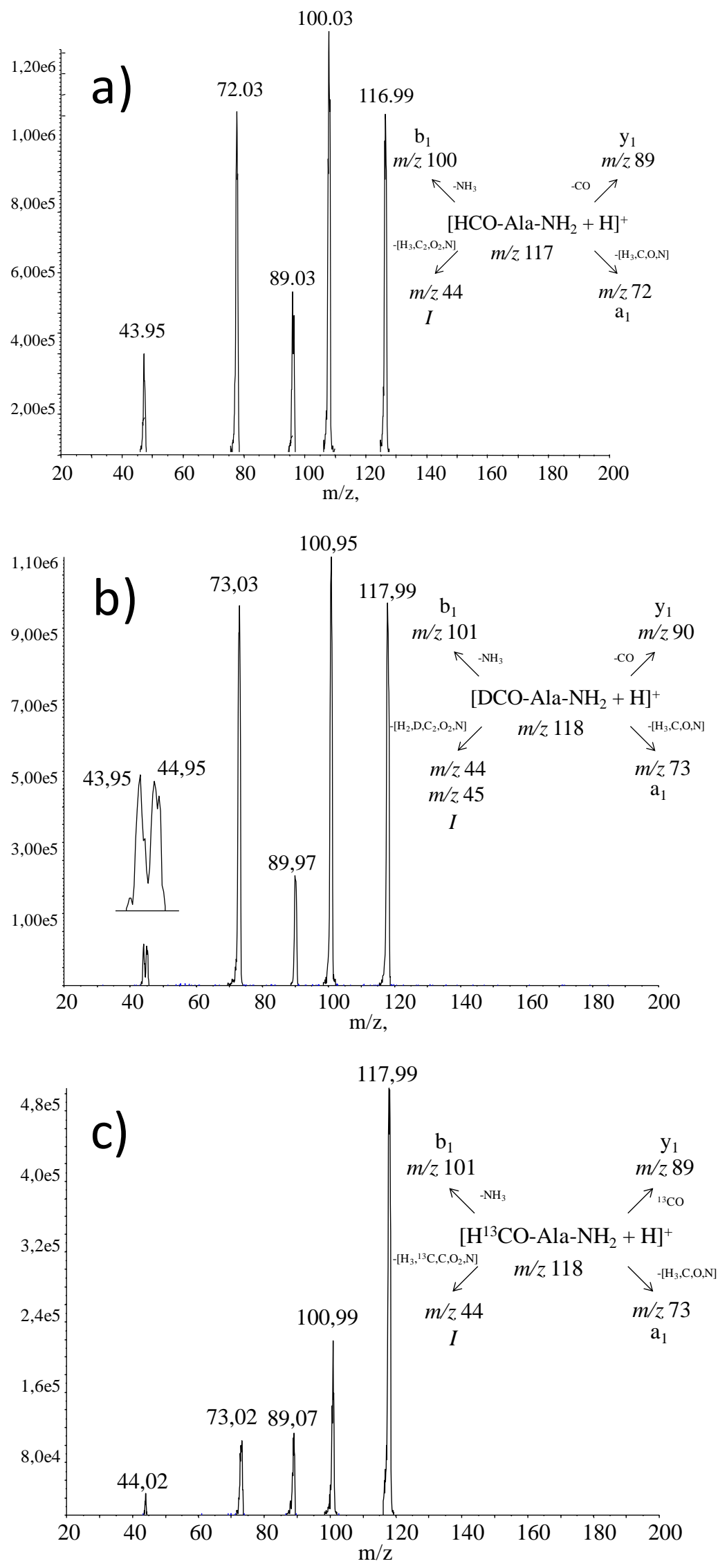

Figure 4 


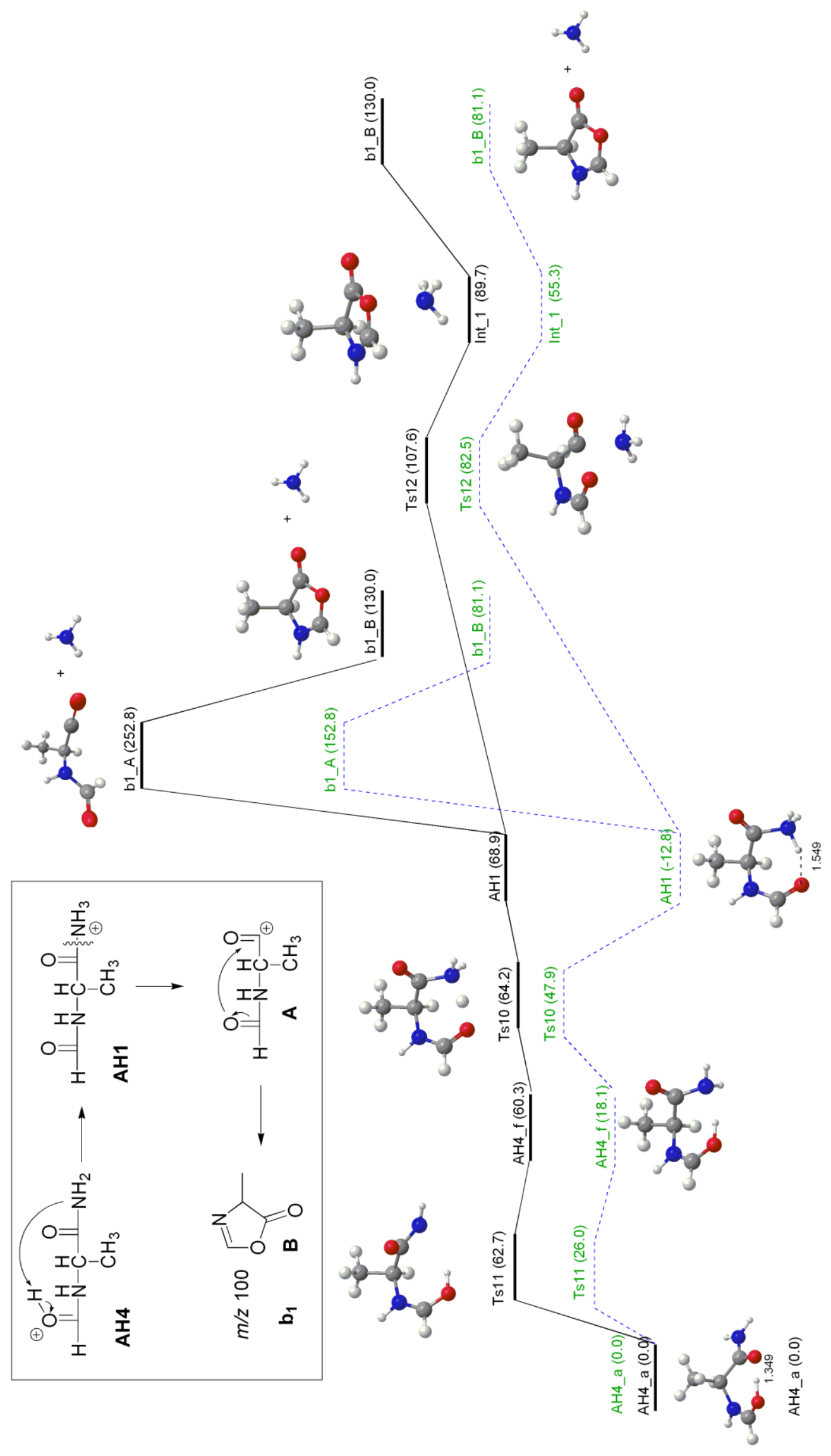

Figure 5 


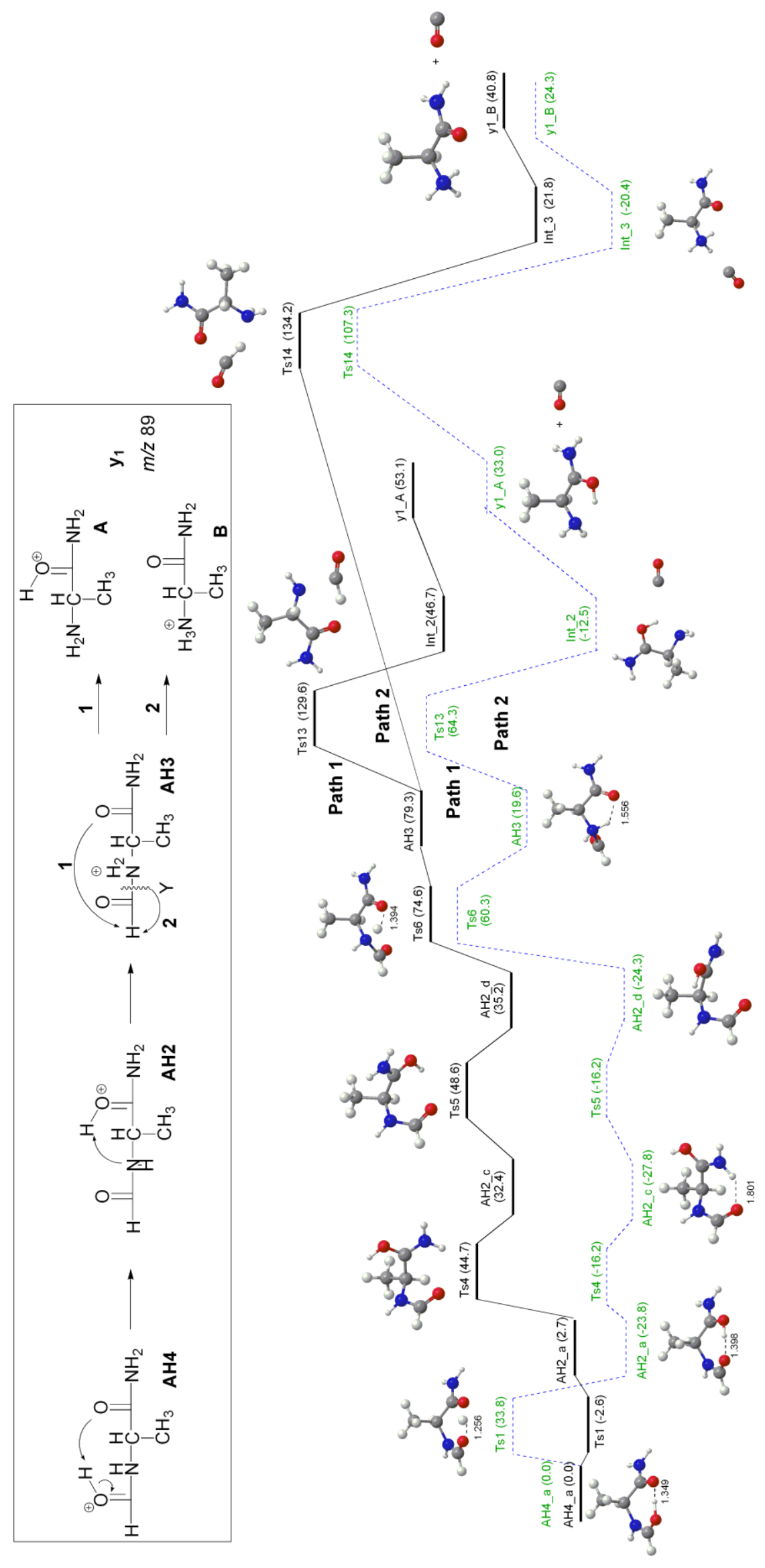

Figure 6 


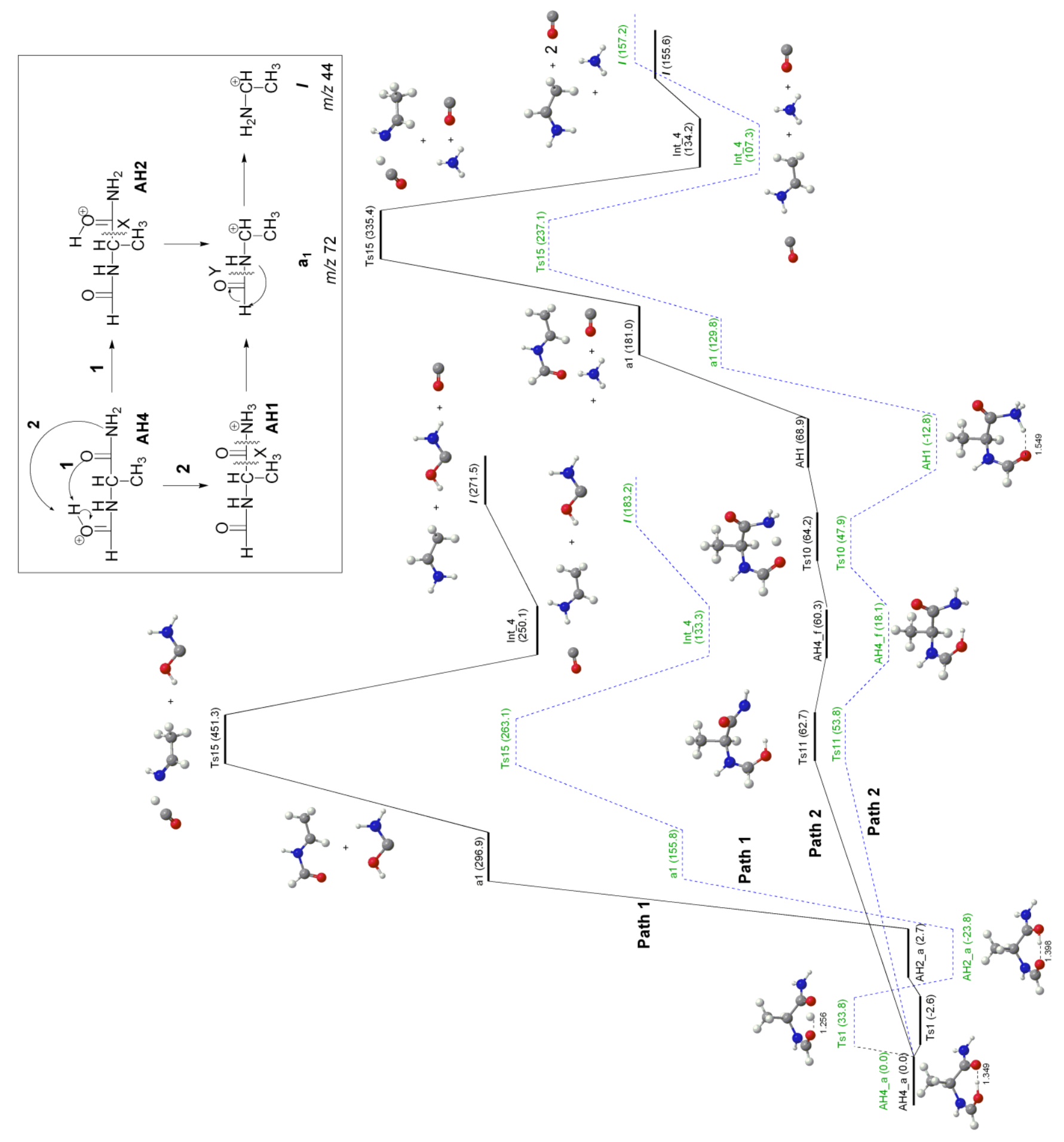

Figure 7 


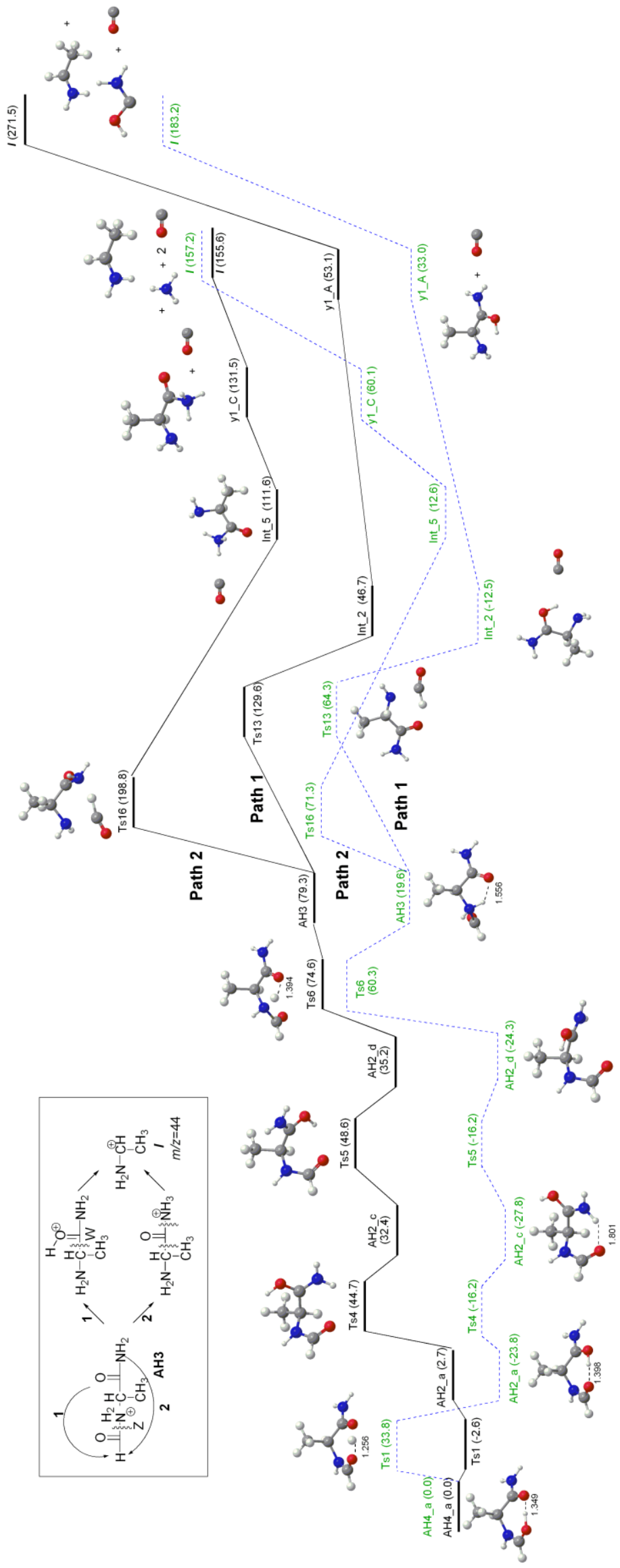

Figure 8 


\begin{tabular}{|l|c|c|c|c|}
\hline Precursor ion & \multicolumn{3}{|c|}{ Product ions } \\
\hline & $\left(\mathrm{b}_{1}\right) ;-\mathrm{NH}_{3}$ & $\left(\mathrm{y}_{1}\right) ;-\mathrm{CO}$ & $\left(\mathrm{a}_{1}\right) ;-\left[\mathrm{H}_{3}, \mathrm{~N}, \mathrm{C}, \mathrm{O}\right]$ & $(I) ;-\left[\mathrm{H}_{3}, \mathrm{C}_{2}, \mathrm{O}_{2}, \mathrm{~N}\right]$ \\
\hline$\left[\left(\mathrm{HCO}-\mathrm{Ala}-\mathrm{NH}_{2}\right) \mathrm{H}\right]^{+}(m / z, 117)$ & $m / z 100$ & $m / z 89$ & $m / z 72$ & $m / z 44$ \\
\hline$\left[\left(\mathrm{DCO}-\mathrm{Ala}-\mathrm{NH}_{2}\right) \mathrm{H}\right]^{+}(m / z, 118)$ & $m / z 101$ & $m / z 90$ & $m / z 73$ & $m / z 44 / 45$ \\
\hline$\left[\left(\mathrm{H}^{13} \mathrm{CO}-\mathrm{Ala}-\mathrm{NH}_{2}\right) \mathrm{H}\right]^{+}(m / z, 118)$ & $m / z 101$ & $m / z 89$ & $m / z 73$ & $m / z 44$ \\
\hline
\end{tabular}

Table 1 


\begin{tabular}{|c|c|c|c|c|c|c|c|}
\hline \multirow[t]{2}{*}{ Product ion } & \multicolumn{7}{|c|}{ Precursor ion } \\
\hline & $\begin{array}{c}\text { Experimental } \\
\text { MS/MS }\end{array}$ & $\begin{array}{c}\mathrm{AH} 4 \_\mathrm{a} \\
(0.0)\end{array}$ & $\begin{array}{c}\mathrm{AH} 4 \_\mathrm{b} \\
(23.7)\end{array}$ & $\begin{array}{c}\mathrm{AH} 2 \_\mathrm{a} \\
(2.7)\end{array}$ & $\begin{array}{c}\mathrm{AH} 2 \_\mathrm{c} \\
(32.4)\end{array}$ & $\begin{array}{l}\text { AH1 } \\
(68.9)\end{array}$ & $\begin{array}{c}\mathrm{AH} 3 \\
(79.3)\end{array}$ \\
\hline $\mathrm{b}_{1}(m / z, 100)$ & $\mathrm{X}$ & $X$ & $X$ & & & $X$ & \\
\hline $\mathrm{y}_{1}(m / z 89)$ & $X$ & $X$ & $X$ & & & & $\mathrm{X}$ \\
\hline $\mathrm{a}_{1} *(m / z 74)$ & & & $\mathrm{X}$ & & $\mathrm{X}$ & & \\
\hline $\mathrm{a}_{1}(m / z 72)$ & $\mathrm{X}$ & $\mathrm{X}$ & $\mathrm{X}$ & $\mathrm{X}$ & $\mathrm{X}$ & $\mathrm{X}$ & $\mathrm{X}$ \\
\hline $\mathrm{X}_{0}(m / z 46)$ & & $X$ & $X$ & $X$ & $X$ & $X$ & $\mathrm{X}$ \\
\hline$I(m / z 44)$ & $X$ & $\mathrm{X}$ & $X$ & $X$ & $\mathrm{X}$ & $X$ & $\mathrm{X}$ \\
\hline $\mathrm{B}_{0}(m / z 29)$ & & & & $X$ & $X$ & $X$ & $X$ \\
\hline
\end{tabular}

Table 2 